\title{
The Evolution of Cash Transactions: Some Implications for Monetary Policy
}

\author{
StACEY L. SCHREFT AND BRUCE D. SMITH ${ }^{*}$ \\ November 1997 \\ Last Revised: February 1999
}

\begin{abstract}
This paper considers the implications for monetary policy of a decreasing demand for outside money. It finds that even perpetual declines in the demand for base money pose no threat to the traditional methods employed for conducting monetary policy. The effects of such reductions in the demand for central bank liabilities, however, do depend on how monetary policy is conducted. Four monetary policy regimes are analyzed. With a policy of nominal-interest-rate targeting, a secular decline in the volume of cash transactions unambiguously leads to accelerating inflation. A policy of maintaining a fixed composition of government liabilities leads to accelerating (decelerating) inflation if agents have sufficiently high (low) levels of risk aversion. Inflation targeting produces falling nominal and real interest rates, while a policy of fixing the rate of money growth can easily lead to indeterminacy and endogenous oscillation in interest rates. It is argued that a policy of fixing the composition of government liabilities has several advantages if it is known that agents are not too risk averse and that the asymptotic demand for base money is small. If this information is not known, then interest-rate or inflation targeting have an advantage because their consequences are not sensitive to such environmental features.
\end{abstract}

\footnotetext{
* Schreft, Research Department, Federal Reserve Bank of Kansas City, Kansas City, MO 64198, 816-881-2581, sschreft@frbkc.org; Smith, Department of Economics, University of Texas, Austin, TX 78712, 512-475-8548, bsmith@mundo.eco.utexas.edu. The views expressed in this paper are not necessarily those of the Federal Reserve Bank of Kansas City or the Federal Reserve System.
} 
It has long been thought that monetary policy affects the macroeconomy by inducing variations in the supply and demand of outside money. ${ }^{1}$ Recently, however, the traditional sources of the demand for outside money have been in pronounced decline. For example, continuous technological improvement in electronics and communication systems has made possible the development of several new, noncash means of payment. As the use of these new payment instruments has grown, there has been a pronounced shift away from the use of cash in transactions. According to The Nilson Report (1997), cash accounted for 20 percent of the dollar volume of U.S. payments made by consumers in 1990 and 18 percent in 1996, and is projected to account for only 16 percent in 2000 and 12 percent in $2005 .^{2}$ At the same time, many countries have eliminated reserve requirements on most or all intermediaries, while other countries that have not done so (like the United States) have permitted financial innovations that render reserve requirements virtually inconsequential. ${ }^{3}$ As a result, it seems entirely possible that the demand for base money may virtually or entirely vanish in the not-too-distant future.

These developments necessitate the reopening of an age-old question in monetary economics: What does a declining demand for base money-and, perhaps, a demand that is declining without limit-imply for monetary policy? ${ }^{4}$ Does it imply that certain methods of conducting monetary policy may become infeasible? Does it mean that some methods may lead to unbounded inflation or indeterminacy? And, must a central bank know whether the use of outside money will disappear altogether or just become minimal in order to determine the best course of action?

This paper proposes a simple framework for thinking about these issues. It begins by presenting a pure-exchange, overlapping-generations model with only two primary assetsgovernment-issued fiat currency and government bonds. To generate a demand for cash transactions, the model incorporates spatial separation and limited communication along the lines

\footnotetext{
${ }^{1}$ For example, Lindsey and Wallich (1989, p. 231) assert that "variations in the supply of reserves relative to the demand for them, with associated impacts on the cost of reserves, other interest rates, and the stock of money, are the initial channels through which most central banks of developed capitalist countries use their policy instruments to affect the macroeconomy."

${ }^{2}$ Cash is used, and will continue to be used in the foreseeable future, for most small consumer transactions. Such transactions constitute the majority of all transactions, but their total dollar value is relatively small (see Nilson 1997).

${ }^{3}$ See Sellon and Weiner (1996).

${ }^{4}$ Wicksell (1898) appears to be the first to consider this question.
} 
of Townsend (1987). To generate a role for banks, the model includes shocks to liquidity needs along the lines of Diamond and Dybvig (1983). Together these features imply a derived demand for base money that depends on the need for currency in payments and the demand by banks for cash reserves. ${ }^{5}$ The volume of cash transactions is then assumed to evolve over time in a way that affects the total demand for base money. ${ }^{6}$

Four conventional methods for conducting monetary policy are considered. The central bank can conduct monetary policy either by setting the mix of government bonds and money outstanding or by setting the money-supply growth rate. Alternatively, it can set either a nominal-interest-rate or an inflation-rate target. To minimize complications, for each policy the central bank is assumed to set only a single once-and-for-all target value for the variable it controls. This differs from Woodford (1998), which allows for policies with feedback rules.

The four major findings can be summarized as follows. First, all of these standard methods for conducting policy are feasible, even in an asymptotically cashless economy, in the following sense. At each date, well-defined conditions determine all real and nominal quantities, and the central bank can achieve its target with conventional open market operations. The implication is that conventional methods for conducting monetary policy can continue to work as expected in the face of a declining demand for base money.

Second, three of the policies considered-inflation targeting, nominal-interest-rate targeting, and fixing the bond-to-money ratio-imply no indeterminacies, even if the demand for base money asymptotically goes to zero. A policy of fixing the money growth rate implies no indeterminacies only if agents are not too risk averse. Otherwise, it does lead to indeterminacies and may also lead to endogenous fluctuations that might not disappear asymptotically. Indeed, monetary fluctuations due to self-fulfilling prophecies can persist indefinitely, even if the demand for base money is declining to zero.

Third, the rate of inflation will necessarily remain bounded under three of the policiesinflation-targeting, interest-rate targeting, and a constant rate of money creation-even if the

\footnotetext{
${ }^{5}$ The model is in fact a pure-exchange version of that in Champ, Smith, and Williamson (1996) and Schreft and Smith $(1997,1998)$.

${ }^{6}$ A related paper is Dow (1995), which studies the effect on the price level of an exogenous decline in the need for cash in a cash-in-advance model without banks. Monetary policy in his model consists of adjustments in the quantity of money accomplished through lump-sum transfers.
} 
demand for base money vanishes in the limit. Under the fourth policy — a fixed bond-to-money ratio-the price level necessarily stabilizes in finite time if cash asymptotically goes out of use and if agents are not too risk averse. When these conditions do not hold, this policy is the only one that leads to unbounded inflation in an aysmptotically cashless economy.

Finally, as the last observation indicates, to predict the consequences of maintaining a fixed bond-to-money ratio, it is necessary to know a good deal about the preferences of bank depositors and the asymptotic magnitude of cash use. The same is true under a policy of fixing the money growth rate, but not with inflation or interest-rate targeting. Since depositor preferences and the long-run demand for cash are difficult to determine with precision, this finding highlights an advantage of inflation or interest-rate targeting.

The question of the welfare consequences of the different policies is more vexing. It will typically not have an unambiguous answer without specifying how the utility of different generations should be weighted. The analysis does, however, yield one conclusion regarding welfare. Of the policies that might be observed in practice (that is, ruling out policies that generate sustained deflation or a zero nominal rate of interest), there is only one that can eliminate the distortions associated with the frictions that generate monetary exchange. It is the policy of fixing the bond-to-money ratio, and it eventually eliminates such distortions only if agents are not too risk averse. But interestingly, these distortions will be eliminated in finite time even if cash never goes out of use, so long as monetary policy is not too "tight" and long-run cash use is not too large.

The remainder of the paper proceeds as follows. Section 1 describes the environment, and section 2 presents the model's equilibrium conditions. Sections 3 through 6 analyze the various monetary policies considered, while section 7 compares the properties of the different policy regimes. Finally, Section 8 concludes by discussing the role that some of the assumptions play in generating the results obtained.

\section{Environment}

Consider an infinite-horizon economy, with $t=1,2, \ldots$ indexing time. The economy consists of two identical islands, each inhabited by an infinite sequence of two-period-lived 
overlapping generations. Each island has, at the start of each date, a continuum of ex ante identical young agents of measure one. At the initial date, each region also has an identical old generation.

Agents are endowed with $\omega>0$ units of the economy's single nonstorable consumption good when young. They have no endowment when old. In addition, they derive utility from consumption only when old, denoted by $c$. The utility function common to all agents is $u(c)=c^{1-\rho} /(1-\rho)$, with $\rho>0$. Because agents care only about consumption when old, they save their entire endowment when young. They hold all their savings, either directly or indirectly, in the economy's primary assets.

Two primary assets are available to agents in the economy: money (fiat currency) and one-period, default-free government bonds. ${ }^{7} M_{t}$ denotes the per capita value of the monetary base on each island, and $B_{t}$ denotes the nominal per capita supply of government bonds. Each bond issued at $t$ is a claim to $I_{t}$ units of currency at $t+1$. Thus, $I_{t}$ is the gross nominal interest rate at $t$. The time $t$ price level is $p_{t}$, which is common across islands. Thus, in real terms, the per capita supplies of money and bonds are $m_{t} \equiv M_{t} / p_{t}$ and $b_{t} \equiv B_{t} / p_{t}$, respectively.

The government, through its central bank, has a variety of monetary policy options. It can fix either the bond-to-money ratio or the rate of money creation. Alternatively, it could target either the nominal interest rate or the inflation rate. Subsequent sections of this article consider each of these policy options. Regardless of what option the government chooses, policy must be conducted so that the government budget constraint is satisfied:

$$
R_{t-1} b_{t-1}=\left(M_{t}-M_{t-1}\right) / p_{t}+b_{t},
$$

where $R_{t-1} \equiv I_{t-1} p_{t-1} / p_{t}$ is the gross real interest rate. $M_{0}>0$ and $B_{0} \geq 0$ are given as initial conditions. $^{8}$

The division of the economy into islands introduces the economically important feature of spatial separation into transactions. There is no communication across islands while transactions are being conducted. Limited communication and spatial separation imply that agents cannot exchange privately issued claims across islands. In addition, money is assumed to

\footnotetext{
${ }^{7}$ Thus far the environment has much in common with Woodford (1998), who also considers a pure exchange economy with bonds and money as the only primary assets.

${ }^{8}$ This modeling of the government essentially consolidates the Treasury and central bank. One can thus think of the central bank here as being able to issue debt if necessary to ensure that it can conduct monetary policy.
} 
be the only asset that can be carried across islands and thus is the only asset that can be used in interlocation exchange. This gives money an advantage over bonds in terms of liquidity, which permits money to be dominated in rate of return. ${ }^{9}$

Each period, after portfolio-allocation decisions are made, a fraction $\pi_{t} \in(0,1)$ of the young agents from each island discover that they have to relocate to the other island before the period ends. Those agents facing relocation have to hold all their wealth in the form of currency when they move or they will be unable to transact on their new island. To capture the evolution of cash transactions in the economy, $\pi_{t}$ is assumed to satisfy

$$
\pi_{t}-\bar{\pi}=\mu\left(\pi_{t-1}-\bar{\pi}\right)
$$

where $\bar{\pi}$ is the long-run value of $\pi_{t}$ and $\mu \in(0,1]$ is a known constant. Thus, $\pi_{t}$ is known at the start of period $t$, although the identities of the specific agents facing relocation are not known.

Equation (2) captures a number of possibilities regarding the evolving role of currency in exchange. When $\mu=1, \pi_{t}$ is constant and the economy is stationary. When $\mu<1$ and $\pi_{1}>\bar{\pi}$, the volume of transactions that require currency shrinks over time. Indeed, when $\bar{\pi}=0$, cash may, and with positive nominal interest rates will, eventually go out of use altogether.

While $\pi_{t}$ is defined as the fraction of agents who are relocated, a secular reduction in $\pi_{t}$ can proxy for a number of scenarios in which improvements in communication and recordkeeping reduce the need for cash in transacting. In one such scenario, all young agents are relocated between periods, with fraction $\pi_{t}$ of them relocated to a part of their destination island where communication is costly enough to preclude the use of checks or other instruments in exchange. A declining value of $\pi_{t}$ thus corresponds to sustained improvements in communication that increase the use of noncash instruments in interlocation exchange.

In any event, the model's assumptions on interlocation exchange imply that agents who learn they will be relocated will want to convert all their assets into currency. Random relocations thus play the same role here that liquidity-preference shocks play in Diamond and Dybvig (1983). And as in Diamond-Dybvig, agents will want to insure against premature asset liquidation. This insurance can be provided efficiently (see Greenwood and Smith 1997) through a bank that announces deposit-return schedules that depend on depositor-withdrawal dates (i.e.,

\footnotetext{
${ }^{9}$ The notion that bonds are not useful in interlocation exchange could be motivated by the realistic assumption that they must be issued in relatively large denominations.
} 
relocation status), takes deposits, and chooses how to allocate the deposited funds between money (that is, cash reserves) and government bonds. There is free entry into banking, so competition ensures that bank profits are zero in equilibrium. As in Diamond-Dybvig, banks of this type intermediate all savings.

Now consider the determination of deposit-return schedules. Let $r_{m}\left(\pi_{t}\right)\left(r_{n}\left(\pi_{t}\right)\right)$ denote the state-contingent gross real return on deposits offered by a typical bank to agents who are (are not) relocated at $t$. Banks announce these returns, taking the returns offered by other banks as given. A Nash equilibrium is a deposit-return schedule $\left(r_{m}\left(\pi_{t}\right), r_{n}\left(\pi_{t}\right)\right)$ for each bank such that, given this return schedule, no other bank has an incentive to alter its set of announced return schedules. Competition among banks for depositors implies that, in equilibrium, banks choose deposit-return schedules to maximize the expected utility of a representative depositor subject to a set of resource constraints, which are described below. Given this behavior by banks, young agents choose to deposit their entire endowment $\omega$, implying that all savings are intermediated. ${ }^{10}$

Next, consider the representative bank's portfolio-allocation decision. Let $m_{t}$ denote the reserves (i.e., real balances) a representative bank chooses to hold per depositor at $t$, and let $b_{t}$ denote the real value of bonds that the bank holds per depositor at $t$. Then $m_{t}$ and $b_{t}$ must satisfy

$$
m_{t}+b_{t} \leq \omega, \quad t \geq 0
$$

By the law of large numbers, a fraction $\pi_{t}$ of a bank's depositors must relocate at $t$. Thus, the representative bank must pay $\pi_{t} r_{m}\left(\pi_{t}\right) \omega$ to those agents at $t$. Relocated agents must be given currency, so the bank's payments to agents who move are constrained by its holdings of reserves:

$$
\pi_{t} r_{m}\left(\pi_{t}\right) \omega \leq m_{t} p_{t} / p_{t+1}, \quad t \geq 0 .
$$

Because agents who move at $t$ carry into $t+1$ the currency they receive upon withdrawing their deposits, the promised return on deposits in (3) includes the gross real return on money, $p_{t} / p_{t+1}$.

To the fraction $1-\pi_{t}$ of a bank's depositors who do not relocate at $t$, the bank must pay $\left(1-\pi_{t}\right) r_{n}\left(\pi_{t}\right) \omega$ upon withdrawal. Assuming that $I_{t}>1$, money is dominated in rate of return, and the bank does not carry cash balances between periods. Payments to nonmovers, then, are

\footnotetext{
${ }^{10}$ If $I_{t}>1$, all young agents strictly prefer intermediated to unintermediated savings at $t$. If $I_{t}=1$, young agents are indifferent between holding bank deposits and holding currency. It is easy to verify that (a) some savings must be intermediated in this case so long as $B_{t}>0$, and (b) there is no loss of generality in assuming that all savings are intermediated.
} 
financed solely with the bank's holdings of bonds; that is, ${ }^{11}$

$$
\left(1-\pi_{t}\right) r_{n}\left(\pi_{t}\right) \omega \leq R_{t} b_{t}, \quad t \geq 0 .
$$

Let $\gamma_{t} \geq 0$ denote the reserve-deposit ratio. Then equations (3) and (4) can be written as

$$
\begin{gathered}
r_{m}\left(\pi_{t}\right) \leq \gamma_{t}\left(p_{t} / p_{t+1}\right) / \pi_{t}, \quad t \geq 0, \\
r_{n}\left(\pi_{t}\right) \leq R_{t}\left(1-\gamma_{t}\right) /\left(1-\pi_{t}\right), \quad t \geq 0 .
\end{gathered}
$$

In a Nash equilibrium, $r_{m}\left(\pi_{t}\right), r_{n}\left(\pi_{t}\right)$, and $\gamma_{t}$ are chosen to maximize

$$
\left\{\pi_{t}\left(r_{m}\left(\pi_{t}\right) \omega\right)^{1-\rho}+\left(1-\pi_{t}\right)\left(r_{n}\left(\pi_{t}\right) \omega\right)^{1-\rho}\right\} /(1-\rho)
$$

subject to (5) and (6). The optimal reserve-deposit ratio for this problem is given by ${ }^{12}$

$$
\gamma_{t}=\frac{1}{1+\left(\frac{1-\pi_{t}}{\pi_{t}}\right) I_{t}^{(1-\rho) / \rho}} \equiv \gamma\left(I_{t}, \pi_{t}\right) .
$$

If $I_{t}>1$ at $t$, it is easy to verify that $r_{m}\left(\pi_{t}\right)<r_{n}\left(\pi_{t}\right)$. In this case, agents receive less than complete insurance against the event of being relocated. The reason is that banks must hold reserves in order to provide insurance coverage, and with $I_{t}>1$, holding reserves involves an opportunity cost that causes agents not to desire complete insurance. If, however, $I_{t}=1$, then it is easy to verify that $r_{m}\left(\pi_{t}\right)=r_{n}\left(\pi_{t}\right)=I_{t} p_{t-1} / p_{t}=p_{t-1} / p_{t}$. The attainment of a zero nominal interest rate thus eliminates a distortion, much as it does in cash-in-advance models.

Some properties of the function $\gamma\left(I_{t}, \pi_{t}\right)$ will be useful for future reference.

Differentiation of (7) establishes that the interest elasticity of reserve demand is

$$
I_{t} \gamma_{1}\left(I_{t}, \pi_{t}\right) / \gamma\left(I_{t}, \pi_{t}\right)=((\rho-1) / \rho)\left[1-\gamma\left(I_{t}, \pi_{t}\right)\right] .
$$

Clearly, $\gamma_{1}\left(I_{t}, \pi_{t}\right) \leq(>) 0$ as $\rho \leq(>) 1$. The ambiguity in the sign of $\gamma_{1}\left(I_{t}, \pi_{t}\right)$ derives from conventional income and substitution effects. A higher value of $I_{t}$, ceteris paribus, increases the opportunity cost of holding reserves. The substitution effect causes banks, acting on behalf of depositors, to substitute away from low-yielding assets. A higher value of $I_{t}$, however, also increases the income a bank earns on its bond holdings. Standard income effects cause the bank to want to raise the consumption of relocated agents, which it can do only by holding more reserves. The substitution (income) effect dominates if $\rho<(>) 1$.

\footnotetext{
${ }^{11}$ If the nominal interest rate is zero, the bank may carry cash reserves between periods. It also is indifferent regarding the composition of its assets. Nonetheless, $m_{t}$ and $b_{t}$ can be determined as part of a general equilibrium. For the sake of brevity, this case is not analyzed here.

${ }^{12}$ Again, this expression applies only if $I_{t}>1$.
} 
In addition, the elasticity of the demand for reserves with respect to the volume of cash transactions is

$$
\pi_{t} \gamma_{2}\left(I_{t}, \pi_{t}\right) / \gamma\left(I_{t}, \pi_{t}\right)=\left[1-\gamma\left(I_{t}, \pi_{t}\right)\right] /\left(1-\pi_{t}\right)>0
$$

Thus, higher relocation probabilities (i.e., a larger volume of transactions that require cash) induce banks to hold higher levels of reserves, other things equal.

Finally, if $\rho \leq(>) 1$, then $\gamma\left(I_{t}, \pi_{t}\right) \in[0, \pi](\in[\pi, 1])$ for all $I_{t}>1$. Intuitively, this property reflects the role that banks play in providing insurance to agents who have to move. When agents are relatively risk averse $(\rho>1)$, banks' reserve-deposit ratios exceed the share of deposits that will be withdrawn early (i.e., $\left.\gamma\left(I_{t}, \pi_{t}\right) \in[\pi, 1]\right)$. This allows banks to pay movers a rate of return on deposits greater than the rate of return on currency, and they pay nonmovers a rate of return less than the rate of return on bonds.

It immediately follows from the relationship between $\rho$ and $\gamma\left(I_{t}, \pi_{t}\right)$ that $\pi_{t} \gamma_{2}\left(I_{t}, \pi_{t}\right) / \gamma\left(I_{t}, \pi_{t}\right) \geq(<) 1$ if $\rho \leq(>) 1$. In other words, the elasticity of reserve demand with respect to $\pi_{t}$ is no less than (less than) one if agents are no more (more) risk averse than they would be with logarithmic utility. ${ }^{13}$ Intuitively, a change in $\pi_{t}$ represents a change in the risk of relocation. As depositors become relatively more risk averse, banks' reserve holdings respond more strongly to such a change.

\section{General Equilibrium}

An equilibrium for the economy described above satisfies three conditions. First, the money market must clear. Given that all beginning-of-period demand for base money derives from banks, if $I_{t}>1$ this requirement implies that

$$
\gamma\left(I_{t}, \pi_{t}\right) \omega=M_{t} / p_{t} \equiv m_{t}, \quad t \geq 1 .
$$

Second, the government-bond market must clear:

$$
\left[1-\gamma\left(I_{t}, \pi_{t}\right)\right] \omega=B_{t} / p_{t} \equiv b_{t}, \quad t \geq 1,
$$

\footnotetext{
${ }^{13}$ Suppose that the environment described above is replaced with the simpler assumption that a cash-in-advance constraint applies to a fraction $\pi_{t}$ of each agent's purchases, with $\pi_{t}$ evolving as in the text. Then the elasticity of the demand for base money with respect to $\pi_{t}$ will be one. As will be apparent from the subsequent discussion, this will substantially reduce the set of possible equilibrium outcomes. See Dow (1995) and Woodford (1998) for formulations of this type.
} 
if $I_{t}>1$. Let $\beta_{t}$ denote the ratio of bonds to money outstanding $\left(b_{t} / m_{t}\right)$. Then (8) and (9) imply that whenever $I_{t}>1, I_{t}$ and $\beta_{t}$ must satisfy the condition

$$
\beta_{t}=\left[1-\gamma\left(I_{t}, \pi_{t}\right)\right] / \gamma\left(I_{t}, \pi_{t}\right), \quad t \geq 1 .
$$

Finally, the government budget constraint, (1), must be satisfied at all dates. Using the definition of $\beta_{t}$, (1) can be written as

$$
m_{t}\left(1+\beta_{t}\right)=m_{t-1}\left[R_{t-1} \beta_{t-1}+\left(p_{t-1} / p_{t}\right)\right], \quad t \geq 2 .
$$

Substituting (8) into (11) and using the relationship $R_{t-1} \equiv I_{t-1} p_{t-1} / p_{t}$ yields the equivalent

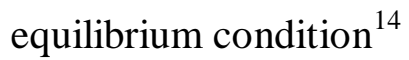

$$
\left(1+\beta_{t}\right) \gamma\left(I_{t}, \pi_{t}\right)=\left(p_{t-1} / p_{t}\right) \gamma\left(I_{t-1}, \pi_{t-1}\right)\left(1+\beta_{t-1} I_{t-1}\right), \quad t \geq 2,
$$

which obtains whenever $I_{t}>1$.

For a given specification of government policy, an equilibrium is a sequence $\left\{I_{t}, p_{t}, \beta_{t}\right\}$ that satisfies (10), (11), and (12) at all dates. The remaining sections of this article characterize the properties of equilibria under alternative assumptions about the conduct of monetary policy.

\section{An Exogenous Bond-to-Money Ratio}

The government could choose to conduct monetary policy by fixing once and for all a value of $\beta$, the bond-to-money ratio. Different choices of $\beta$ correspond to different open market stances: high (low) values of $\beta$ are associated with tight (loose) monetary policy, as conventionally conceived. For such a policy regime, the following result obtains:

PROPOSITION 1: When the demand for cash for transactions is decreasing over time, a policy that fixes the bond-to-money ratio leads to secularly rising (falling) interest rates and inflation depending on whether $\rho>(<)$ 1. If the asymptotic use of currency is (is not) small enough, then the nominal interest rate and the inflation rate approach zero (remain positive).

With $\beta$ fixed, equations (1) and (10) indicate that the nominal interest rate must adjust to keep the ratio of reserve demand to bond demand equal to the ratio of reserve supply to bond

\footnotetext{
${ }^{14}$ The appropriate version of this condition for the initial date, $t=1$, is $\left(1+\beta_{1}\right) \gamma\left(I_{1}, \pi_{1}\right)=M_{0} / p_{1}$, with $M_{0}>0$ exogenously given.
} 
supply. Thus, whenever the nominal interest rate is positive, it must evolve according to

$$
I_{t}=\left[\beta\left(\pi_{t} /\left(1-\pi_{t}\right)\right)\right]^{\rho /(1-\rho)}, \quad t \geq 1 .
$$

Equation (12) then determines the sequence of inflation rates:

$$
p_{t} / p_{t-1}=\left(1+\beta I_{t-1}\right) /(1+\beta), \quad t \geq 2 .
$$

Substituting (13) into (14) yields the following closed-form expression for $p_{t+1} / p_{t}$ :

$$
p_{t+1} / p_{t}=\frac{1+\beta^{1 /(1-\rho)}\left(\pi_{t} /\left(1-\pi_{t}\right)\right)^{\rho /(1-\rho)}}{(1+\beta)}, t \geq 1 .
$$

Furthermore, the real rate of interest, $R_{t}$, evolves according to $R_{t}=I_{t} p_{t} / p_{t+1}=(1+\beta) I_{t} /\left(1+\beta I_{t}\right)$.

The real interest rate thus inherits the behavior of the nominal interest rate. The evolution of $I_{t}$ and $p_{t+1} / p_{t}$ depends on the magnitudes of $\bar{\pi}$ and $\rho$. There are two cases.

\section{Case 1: $\rho<1$}

From (13) and (14), when $\rho<1$ a declining role for currency in the payments system must lead to a nominal interest rate and inflation rate that are falling over time. The question remains of how far they will fall. If $\beta \bar{\pi} /(1-\bar{\pi})<1$, so that the asymptotic use of currency in payments is sufficiently small, then (13) implies that there exists a finite date, denoted by $T$, such that $I_{t}=1$ for all $t \geq T$. Once the nominal interest rate ceases to be positive, the derivation of equilibrium above is no longer valid. However, it is not hard to show that, with $\beta \bar{\pi} /(1-\bar{\pi})<1$, $I_{t}=1=p_{t} / p_{t+1}$ must obtain for all $t \geq T$. Both the nominal interest rate and the inflation rate therefore decline over time until, at some finite date, the opportunity cost of holding money is zero. At that point, agents have no incentive to economize further on the use of currency. The price level stabilizes at its date- $T$ value. It is noteworthy that this result is completely independent of the value of $\beta$. Thus, regardless of the "looseness" or "tightness" of monetary policy, the price level ultimately stabilizes. However, the larger $\beta$ is, the longer is the period of time over which a positive nominal interest rate can be observed. Also noteworthy is the fact that $I_{t}$ must eventually equal one even if $\bar{\pi}>0$ holds, so long as $\beta \bar{\pi} /(1-\bar{\pi})<1$. This means that the attainment of a zero nominal interest rate and price stability does not require that the fraction of transactions requiring cash goes to zero. It also means that in finite real time banks will provide complete insurance. 
In contrast, when $\beta \bar{\pi} /(1-\bar{\pi})>1$, so the asymptotic use of currency remains sufficiently large, (13) implies that $I_{t}>1$ for all $t$. It also implies that $I_{t}$ declines monotonically, as does the inflation rate. Equation (15) implies that $p_{t+1} / p_{t}$ asymptotically approaches $\left[1+\beta^{1 /(1-\rho)}(\bar{\pi} /(1-\bar{\pi}))^{\rho /(1-\rho)}\right] /(1+\beta)>1$. Thus, whatever the asymptotic use of currency, a diminishing role for currency in transactions leads to a declining nominal interest rate and inflation rate.

\section{Case 2: $\rho>1$}

When $\rho>1$, (13) implies that $I_{t}$ must be rising over time. Equation (15) implies that the rate of inflation must also be rising. Consequently, a declining demand for currency in transactions leads to a monotonically increasing nominal interest rate and accelerating inflation.

To summarize, when the central bank fixes the bond-to-money ratio, the effects of a diminishing role for currency in transactions depend heavily on the magnitude of $\rho$. When $\rho<$ (>) 1, the substitution (income) effect dominates in the response of reserve demand to a change in the nominal interest rate, so as $\pi_{t}$ falls, the nominal rate declines (rises). And because the interest elasticity of reserve demand is less than (greater than) zero when $\rho<(>) 1$, a declining (rising) nominal interest rate is associated with a declining (rising) inflation rate and real rate of interest.

\section{Nominal-Interest-Rate Targeting}

Alternatively, the central bank could conduct monetary policy so as to maintain a constant value $I>1$ for the gross nominal interest rate. ${ }^{15}$ The following proposition summarizes the effect of a declining demand for currency for transactions under such a policy.

PROPOSITION 2: A central bank that pegs the nominal interest rate in the face of a declining

\footnotetext{
${ }^{15}$ As mentioned previously, the effect of implementing the Friedman rule (a target of $I=1$ ) is not considered here. Nevertheless, the results in this section apply to policies that approximate the Friedman rule arbitrarily closely.
} 
$\pi_{t}$ must continuously increase the bond-to-money ratio and must do so at a more rapid rate than the contraction in the demand for reserves. Because the supply of base money decreases less rapidly than the demand for reserves, the interest-rate peg commits the economy to secularly rising inflation.

To derive this result, observe that equations (1) and (10), with $I$ constant, imply that $\beta_{t}$ must satisfy

$$
\beta_{t}=\left(\left(1-\pi_{t}\right) / \pi_{t}\right) I^{(1-\rho) / \rho} .
$$

Thus, as $\pi_{t}$ declines, the central bank must raise the bond-to-money ratio to keep the nominal interest rate constant. In effect, then, the central bank must drain base money from the economy via open market sales. This is true regardless of the magnitude of $\rho$.

In addition, (10) with $I_{t}=I$ describes the evolution of the demand for reserves. As noted previously, when the nominal interest rate is constant, a secular decline in the value of $\pi_{t}$ induces a less (more) than proportional decline in reserve demand if $\rho>(<) 1$. Thus, the demand for base money may decline either more rapidly or more slowly than the volume of cash transactions. Differentiation of (16) establishes that $\left(\pi_{t} / \beta_{t}\right)\left(d \beta_{t} / d \pi_{t}\right)=-\left(1-\pi_{t}\right)^{-1}$. The central bank therefore must increase the bond-to-money ratio more rapidly than the volume of cash transactions contracts if it is to peg the nominal interest rate successfully.

With respect to the rate of inflation, (16) and (12) imply that

$$
p_{t} / p_{t-1}=I-(I-1) \gamma\left(I, \pi_{t-1}\right)=\frac{1+\left(1-\pi_{t-1} / \pi_{t-1}\right) I^{1 / \rho}}{1+\left(1-\pi_{t-1} / \pi_{t-1}\right) I^{(1-\rho) / \rho}}, \quad t \geq 2 .
$$

Since $\gamma_{2}\left(I, \pi_{t-1}\right)>0$, it follows from (17) that the equilibrium inflation rate must be rising over time as $\pi_{t-1}$ declines. Intuitively, the supply of base money decreases less rapidly than the demand for reserves, driving the inflation rate up over time. With I constant, it follows that the real interest rate declines over time along with $\pi_{t-1}$. Both statements hold regardless of the magnitude of $\rho$.

If $\bar{\pi}=0$, so that asymptotically cash use is zero when $I>1,(17)$ implies that $\lim _{t \rightarrow \infty} p_{t} / p_{t-1}=I$ and thus that the gross real interest rate approaches one. However, with $I>1$, banks provide incomplete insurance against relocation, even asymptotically. Under nominal- 
interest-rate targeting then, economic distortions do not vanish with the elimination of cash transactions.

\section{Inflation Targeting}

The central bank also could follow a policy of setting the inflation rate, $p_{t} / p_{t-1}$, equal to $\phi$ for all $t \geq 1$. Assuming that $\phi \geq 1$, so the central bank does not attempt to generate deflation, the following result obtains.

PROPOSITION 3: If the central bank targets the inflation rate, the nominal interest rate decreases (increases) as $\pi_{t}$ decreases (increases).

To see this, notice that equations (10) and (12) imply the satisfaction of the following condition at each date:

$$
1=(1 / \phi)\left[I_{t}-\left(I_{t}-1\right) \gamma\left(I_{t}, \pi_{t}\right)\right] .
$$

If $\phi>1$ and/or $\bar{\pi}>0$, then (18) necessarily has a unique solution with $I_{t}>1$ in every period.

Now consider the effect of changes in the demand for currency in transactions on the equilibrium evolution of the nominal interest rate. Differentiation of (18) yields

$$
\begin{aligned}
d I_{t} / d \pi_{t} & =\frac{\left(I_{t}-1\right) \gamma_{2}\left(I_{t}, \pi_{t}\right)}{1-\gamma\left(I_{t}, \pi_{t}\right)-\left(I_{t}-1\right) \gamma_{1}\left(I_{t}, \pi_{t}\right)} \\
& =\frac{\left(I_{t}-1\right) \gamma_{2}\left(I_{t}, \pi_{t}\right)}{\left[1-\gamma\left(I_{t}, \pi_{t}\right)\right]\left[1-\left(\frac{\rho-1}{\rho}\right)\left(\frac{I_{t}-1}{I_{t}}\right) \gamma\left(I_{t}, \pi_{t}\right)\right]} .
\end{aligned}
$$

Proposition 3 follows immediately since $\gamma_{2}\left(I_{t}, \pi_{t}\right)>0$ and $1>[(\rho-1) / \rho]\left[\left(I_{t}-1\right) / I_{t}\right] \gamma\left(I_{t}, \pi_{t}\right)$. Intuitively, as the demand for cash for transactions falls, the demand for reserves falls and the demand for bonds rises. Given the inflation tax rate, then, seigniorage revenue decreases, so the nominal and real interest rate must decline along with $\pi_{t}$ to satisfy the government budget constraint.

Proposition 3 has a corollary: With a fixed inflation rate, as $\pi_{t}$ declines, the real interest rate necessarily falls over time. This consequence of a diminishing role of currency in 
transactions was also observed under a nominal-interest-rate target.

It remains to consider how the bond-to-money ratio must evolve to keep the inflation rate at its target level. It is easily established that $d \beta_{t} / d \pi_{t}<0$, so the central bank must continuously raise the ratio to maintain its target.

When $\bar{\pi}=0,(18)$ implies that $\lim _{t \rightarrow \infty} I_{t}=\phi$. Thus, if $\phi>1$, so some inflation occurs, the nominal interest rate remains positive at all dates. The gross real interest rate asymptotically approaches one. In effect, then, the situation under an inflation target closely resembles that under an interest-rate target.

\section{A Constant Rate of Money Creation}

Instead of targeting the inflation rate, the central bank could set, once and for all, a rate of growth for the money supply. In particular, if the monetary base evolves according to

$$
M_{t+1}=\sigma M_{t}, \quad t \geq 1,
$$

with $M_{0}>0$ given and $\sigma>1$, then the effects of a declining demand for currency for transactions are more complicated, as the following proposition indicates.

PROPOSITION 4: When the central bank fixes the money growth rate, both steady state and dynamical equilibria are possible. In a steady state the inflation rate and nominal interest rate are increasing in the money growth rate. The nature of dynamical equilibria depends on the value of $\rho$. If $\rho$ is sufficiently small, there is a unique equilibrium that monotonically converges to the steady state. If it is sufficiently large, many oscillatory equilibrium paths can approach the steady state.

The argument underlying Proposition 4 proceeds as follows. With a constant rate of money creation, the real return on reserve holdings is given by

$$
\frac{p_{t-1}}{p_{t}}=\frac{m_{t}}{\sigma m_{t-1}}=\frac{\gamma\left(I_{t}, \pi_{t}\right)}{\sigma \gamma\left(I_{t-1}, \pi_{t-1}\right)}, \quad t \geq 2
$$

Using (19) and (10) in (12) gives the equilibrium law of motion for $I_{t}$ when $I_{t}>1$ : 


$$
\frac{\sigma}{\gamma\left(I_{t}, \pi_{t}\right)}=1+I_{t-1}\left[\frac{1-\gamma\left(I_{t-1}, \pi_{t-1}\right)}{\gamma\left(I_{t-1}, \pi_{t-1}\right)}\right]=1+\left(\frac{1-\pi_{t-1}}{\pi_{t-1}}\right) I_{t-1}^{1 / \rho}, \quad t \geq 2 .
$$

Equations (2) and (20) govern the evolution of the sequence $\left\{I_{t}, \pi_{t}\right\}$.

\section{A. Steady-State Equilibria with $\bar{\pi}>0$}

In a steady state, $\pi_{t}=\bar{\pi}>0$. Imposing $\pi_{t}=\pi_{t-1}=\bar{\pi}$ and $I_{t}=I_{t-1}=I$ in (20) yields the condition that determines the steady-state nominal interest rate:

$$
\left(\frac{\bar{\pi}}{1-\bar{\pi}}\right)(\sigma-1)=I^{1 / \mathrm{\rho}}\left[1-\left(\frac{\sigma}{I}\right)\right] .
$$

This equation has a unique solution satisfying $I>\sigma>1$. In addition, higher values of $\sigma$ lead to higher values of the steady-state nominal interest rate and the rate of inflation. The steady-state real interest rate rises when $\sigma$ is increased iff $(1-\rho) \sigma>1$. For future reference, observe that $I>$ $\sigma>1$ even for arbitrarily small positive values of $\bar{\pi}$. But as $\bar{\pi} \rightarrow 0, I \rightarrow \sigma$.

\section{B. Dynamics with $\bar{\pi}>0$}

Simple algebraic manipulation establishes that equation (20) can be written as

$$
\begin{aligned}
I_{t}^{(1-\rho) / \rho} & =\left(\frac{\pi_{t}}{1-\pi_{t}}\right)\left[\left(\frac{1}{\sigma}\right)\left(\frac{1-\pi_{t-1}}{\pi_{t-1}}\right) I_{t-1}^{1 / \rho}-\left(\frac{\sigma-1}{\sigma}\right)\right] \\
& =\left[\frac{\mu \pi_{t-1}+(1-\mu) \bar{\pi}}{1-\mu \pi_{t-1}-(1-\mu) \bar{\pi}}\right]\left[\left(\frac{1}{\sigma}\right)\left(\frac{1-\pi_{t-1}}{\pi_{t-1}}\right) I_{t-1}^{1 / \rho}-\left(\frac{\sigma-1}{\sigma}\right)\right], \quad t \geq 2 .
\end{aligned}
$$

Linearizing (22) in a neighborhood of the steady state yields the dynamical system $\left(I_{t}-I, \pi_{t}-\bar{\pi}\right)^{\prime}=J\left(I_{t-1}-I, \pi_{t-1}-\bar{\pi}\right)^{\prime}$, where $J$ is the Jacobian matrix

$$
J=\left|\begin{array}{cc}
\frac{\partial I_{t}}{\partial I_{t-1}} & \frac{\partial I_{t}}{\partial \pi_{t-1}} \\
0 & \mu
\end{array}\right|,
$$

with all partial derivatives evaluated at the steady state. Clearly the eigenvalues of $J$ are $\mu$ and $\left.\frac{\partial I_{t}}{\partial I_{t-1}}\right|_{I_{t-1}=I}=\left(\frac{1}{1-\rho}\right)\left(\frac{I}{\sigma}\right)$. Since $I / \sigma>1$ in a steady state, there are two possibilities regarding equilibrium dynamics. 
Case 1: $\rho<1$

When $\rho<1, \partial I_{t} / \partial I_{t-1}=[1 /(1-\rho)](I / \sigma)>1$. It follows that the steady state is a saddle. Since $I_{1}$ is an endogenous initial condition, the equilibrium value $I_{1}$ must place the economy on its stable manifold. Consequently, there is a unique equilibrium, and that equilibrium displays monotonic convergence to the steady state.

\section{Case 2: $\rho>1$}

When $\rho>1, \partial I_{t} / \partial I_{t-1}=[1 /(1-\rho)](I / \sigma)<0$. The steady state is a sink (saddle) if $I / \sigma<(>) \rho-1$. Moreover, using equation (21), I/ $\sigma<(>) \rho-1$ iff $(\bar{\pi} / 1-\bar{\pi})((\sigma-1) / \sigma)<$ $(>)(\rho-2)[\sigma(\rho-1)]^{(1-\rho) / \rho}$. Clearly, the steady state is a sink if $\rho>2$, and if either $\bar{\pi}$ is sufficiently close to zero or $\sigma$ is sufficiently close to one.

When $I / \sigma<\rho-1$, any choice of $I_{1}$ sufficiently close to $I$ allows the steady state to be approached, so dynamical equilibria are indeterminate. Moreover, equilibrium paths approaching the steady state will display oscillations. In other words, endogenously arising volatility will be observed. That is, whenever $\rho>2$, and whenever the asymptotic use of currency is sufficiently small, a fixed money growth rate must lead to a situation of indeterminacy and endogenous volatility. Both the nominal rate of interest and the price level must fluctuate along any equilibrium path.

Note that the endogenous volatility that emerges might not vanish asymptotically. Indeed, for certain values of $\bar{\pi}$, and for fixed values of $\sigma$, there will exist equilibria displaying two-period cycles. Thus, the policy of fixing a rate of money growth can easily lead to the existence of permanent fluctuations. Such fluctuations cannot occur under the other policy regimes analyzed.

\section{An Asymptotically "Cashless" Economy}

When $\bar{\pi}=0$, (22) reduces to

$$
I_{t}^{(1-\rho) / \rho}=\left(\frac{\mu}{\sigma}\right)\left[1+(1-\mu)\left(\frac{\pi_{t-1}}{1-\pi_{t-1}}\right)\right]^{-1} I_{t-1}^{1 / \rho}-\left(\frac{\mu}{\sigma}\right)(\sigma-1) \frac{\pi_{t-1}}{1-\mu \pi_{t-1}}, \quad t \geq 2 .
$$


In a steady state then, $\pi_{t}=0$ and $I_{t}=\sigma / \mu$. It is possible to show that there is no equilibrium with $I_{t}=1$ for $t$ sufficiently large. That is, the nominal interest rate cannot converge to zero, asymptotically or otherwise. Thus, as in Woodford (1998), the "cashless-limit economy" (i.e., one with $\bar{\pi}=0$ ) has a steady state nominal and real interest rate that is not the limiting solution of (21) as $\bar{\pi} \rightarrow 0$. Nevertheless, the qualitative behavior of economies with $\bar{\pi}>0$ is similar to that of economies with $\bar{\pi}=0$.

With respect to dynamics, it is similarly straightforward to verify that

$\left.\frac{\partial I_{t}}{\partial I_{t-1}}\right|_{I_{t-1}=\sigma / \mu}=(1-\rho)^{-1}$. Thus, if $\rho<1$, the steady state is a saddle. The dynamical equilibrium is unique, and monotonic convergence to the steady state is observed. If $\rho>2$, then the steady state is a sink. There is then an indeterminacy of equilibrium, and paths approaching the steady state display damped oscillation.

Finally, it is clear that as $\rho$ varies, a flip bifurcation can occur, so that undamped oscillation in interest rates and inflation is possible. These monetary fluctuations can therefore be observed even in an asymptotically cashless economy.

\section{Comparison of Policy Regimes}

Three key findings arise from the analysis of the preceding sections. First, a declining demand for outside money does not imply that any of the conventional methods of conducting monetary policy will cease to be feasible. This is true even if the demand for base money declines without limit. Second, the impact of a declining demand for currency for transactions varies considerably across the policy regimes considered. The equilibrium time paths for the interest rate, the inflation rate, and the composition of government liabilities are quite different across the regimes, and one method for conducting policy allows considerable scope for the indeterminacy of equilibrium and for endogenously generated volatility, while the others do not. Third, one method for conducting policy can result in price stability and zero nominal interest rates in finite time if $\bar{\pi}$ is sufficiently small, independent of the choice of policy parameter. Other policies do not share this feature. 
In general, it is quite difficult to rank the various policies on the basis of welfare. To conduct a welfare analysis, one must first find a way to make the stance of monetary policy comparable across policy regimes. One way this can be done is by ensuring that the steady state interest rate arising under each policy is about the same. When this is done, the differences in welfare across regimes are found to be relatively minor and no uniform ranking of the regimes emerges.

One unambiguous statement can be made, however. When $\rho<1$ and $\beta \bar{\pi} /(1-\bar{\pi})<1$, price stability and a zero nominal interest rate are attained in finite time under a policy that maintains a fixed bond-money ratio. A zero nominal interest rate is attractive because it allows banks to provide complete insurance provision against the risk of relocation. If $\bar{\pi}=0$, then there will be a finite date $\bar{T}$ such that for all $t \geq \bar{T}$, young agents unambiguously prefer a policy of fixing the bond-money ratio to a policy of targeting either the nominal rate of interest or the inflation rate. Thus, in an asymptotically cashless economy, ultimately agents will prefer the policy of fixing the bond-money ratio to either a nominal-interest-rate or inflation-rate target. Matters are quite different, however, when $\rho>1$. A policy of fixing the bond-to-money ratio leads to an ever rising nominal interest rate. This will not be the case under nominal-interest-rate targeting or inflation targeting.

This and the earlier observations suggest the following conclusion. Under the policy of

maintaining a fixed bond-to-money ratio—or under a policy of maintaining a fixed rate of money growth — the policy authority must know a good deal about $\rho$ and $\bar{\pi}$ to predict the consequences of the policy. This is not true of interest-rate or inflation targeting. The lack of ambiguity regarding economic dynamics under those policies seems to be a point in their favor.

\section{Concluding Remarks}

The preceding analysis abstracts from several features that are relevant to modern-day payment systems. For example, the focus on a pure-exchange economy makes it impossible for developments in the technology of payments to affect the level of production. Endogenizing production levels would allow the evolution of cash transactions to affect real activity, which in 
turn might modify some conclusions about how this evolution affects the behavior of the price level or the behavior of real and nominal interest rates. And by allowing for capital accumulation, the model would intrinsically have much richer dynamics.

A second feature from which the model abstracts is the mechanism by which the demand for cash evolves. One can regard the specification of an exogenous law of motion for $\pi_{t}$ as a "reduced-form" approach that implicitly takes no stand on the economic forces governing the use of cash in transactions. Clearly, it would be more satisfying to model these forces explicitly. Likewise, it would be better to model the choice between cash and other instruments to make payments. Modeling that choice (for example, as done in Schreft 1992 and Ireland 1994) would endogenize the evolution of cash use and might not alter any of the results derived above.

Third, the model abstracts from the existence of a market in which reserves can be borrowed and lent. The presence of such a market has in principle the potential to substantially affect the demand by banks for reserves. And reserve demand is at the heart of the analysis here.

Introducing a market for reserves into the model is straightforward. The most natural approach is to assume that each bank faces a stochastic demand for cash withdrawals (that is, a random value of $\pi_{t}$ ), but that there is no aggregate randomness. This introduces an additional feature into a bank's decision regarding its reserve holdings: banks face uncertainty regarding withdrawal demand. If banks must choose their reserve-deposit ratio before observing their withdrawal demand, then ex post some banks will have more, and some will have fewer, reserves than needed to pay depositors. This fact leads naturally to the introduction of a market in which banks with a reserve surplus (deficit) can lend (borrow) reserves.

While the introduction of a stochastic withdrawal demand and a market for reserves that resembles today's federal funds market adds some notational complexity, it does not alter the fundamental behavior of the model. Indeed, all the results reported above have close analogs when these additional features are added. Thus, abstracting from a market for reserves does not affect any qualitative conclusions about how an evolving demand for cash transactions affects the economy under alternative methods of conducting monetary policy.

Finally, in this economy all financial transactions are conducted through banks. If the model were modified to allow for a richer set of financial institutions, agents could very well have access to financial instruments that help them overcome the spatial separation and limited 
communication critical to their demand for cash for transactions. The introduction into the economy of such new financial instruments likely would lead to a faster reduction in the use of cash over time, although the implications of this observation for the conduct of monetary policy are by no means clear.

\section{References}

Champ, Bruce; Smith, Bruce D., and Stephen D. Williamson, 1996. "Currency Elasticity and Banking Panics: Theory and Evidence," Canadian Journal of Economics, November, 29(4), 828-864.

Diamond, Douglas, and Philip Dybvig, 1983. "Bank Runs, Deposit Insurance, and Liquidity," Journal of Political Economy, June, 91(3), 401-19.

Dow, James P., Jr., 1995. “A Model of the Transition to a World without Money,” Mimeo, October.

Greenwood, Jeremy, and Bruce D. Smith, 1997. "Financial Markets in Development, and the Development of Financial Markets," Journal of Economic Dynamics and Control, January, 21(1), 145-81.

Ireland, Peter N., 1994. "Economic Growth, Financial Evolution, and the Long-Run Behavior of Velocity," Journal of Economic Dynamics and Control, May/July, 18(3/4), 815-48.

Lindsey, David E., and Henry C. Wallich, 1989. "Monetary Policy." In The New Palgrave Money, edited by John Eatwell, Murray Milgate, and Peter Newman. New York: W.W. Norton.

The Nilson Report, November 1997, p. 6.

Schreft, Stacey L., 1992. "Transaction Costs and the Use of Cash and Credit," Economic Theory, April, 2(2), 283-96.

Schreft, Stacey L., and Bruce D. Smith, 1997. “Money, Banking, and Capital Formation,” Journal of Economic Theory, March, 73(1), 157-82.

Schreft, Stacey L., and Bruce D. Smith, 1998. "The Effects of Open Market Operations in a Model of Intermediation and Growth," Review of Economic Studies, 65(3), 519-550. Sellon, Gordon H., Jr., and Stuart E. Weiner, 1996. “Monetary Policy Without Reserve 
Requirements: Analytical Issues," Federal Reserve Bank of Kansas City Economic Review, Fourth Quarter, 81(4), 5-24.

Townsend, Robert M., 1987. "Economic Organization with Limited Communication," American Economic Review, December, 77(5), 954-71.

Wicksell, Knut, 1898. Interest and Prices. Translated and republished 1936; reprinted 1962. New York: Augustus M. Kelley, Chapter 6.

Woodford, Michael, 1998. "Doing without Money: Controlling Inflation in a Post-Monetary World," Review of Economic Dynamics, January, 1(1), 173-219. 